\title{
Analysis of structural differences of Ag Nanoparticles generated using Thermal and E-beam process based on SEM image
}

\author{
Mainak Saha ${ }^{1}$ \\ ${ }^{1}$ Dept of Metallurgical and Materials Engineering, \\ NIT, Durgapur, West Bengal, India \\ mainaksaha1995@gmail.com
}

\author{
Suvojit Acharjee ${ }^{2}$ \\ ${ }^{2}$ Dept of ETCE, Jadavpur University, \\ Jadavpur University, West Bengal, India \\ acharjeesuvo@gmail.com
}

\author{
Simrat Singh ${ }^{1}$ \\ ${ }^{1}$ Dept of Metallurgical and Materials Engineering, \\ NIT, Durgapur, West Bengal, India \\ ssimrat1996@gmail.com
}

\author{
Chandrasekhar Kandagatla ${ }^{3}$ \\ ${ }^{3}$ Dept of Electronics and Communication Engineering, \\ Aurora's Engineering College, Bhongir, Telangana, India \\ $\underline{\text { Kcs1011@gmail.com }}$
}

Shubhro Chakrabartty ${ }^{3 *}$

${ }^{3}$ Dept of Electronics and Communication Engineering,

Aurora's Engineering College, Bhongir, Telangana, India

\section{*Corresponding author: shubhroacumen@gmail.com}

Abstract: The variation in applications of nanoparticles (NPs) comes from differences in their microstructures. This may be observed in the terms of variation in size, area fraction and even the morphology of the particles. It is mainly the size and topography of these particles which govern the Mechanical, Optoelectronics, properties and have a huge impact in Bio-medical engineering.

Keywords—Nanoparticles, GLAD, SEM etc.

\section{INTRODUCTION}

Nano range structures are formed by different methods for different applications such as optoelectronics, bio-medical purposes and many others. The size of nanoparticles mostly plays a critical role in the various application such as optics, electronics, data storage and anti-bacterial activity. [1]

Lots of techniques are induced to develop nanoparticles such as chemical process [2], RF sputtering [3] and by different physical routes etc. $[4,5]$. But glancing angle deposition gives some special advantage of mechanism to create nanostructures [6]. The morphology of the nanostructures depends on rate of deposition, deposition angle, substrate temperature [7] and rotation rate.

In this work we have shown the comparative study of research on morphological structure of Silver (Ag) nanoparticles (NPs) grown by Electron beam evaporator and Thermal Evaporator and further the structural calculation of Nanoparticles was done by Image processing in MATLAB- R 2017.

\section{EXPERIMENTAL PROCEDURE}

The Ag Nanoparticles were fabricated by both Ebeam and thermal deposition methods keeping same condition. 
Proceedings of the 2nd International Conference on Inventive Computation Technologies ( ICICT 2017) IEEE Xplore Compliant - Part Number:CFP17K52-ART, ISBN:978-1-5090-6697-1

\section{a) Electron beam evaporator:}

The GLAD technique has been carried out to synthesize the pure Ag (MTI, USA) NPs on n-type $\mathrm{Si}\langle 100\rangle$ substrate. The substrates were rotated azimuthally with constant speed of $460 \mathrm{rpm}$ at an orientation of $85^{\circ}$ with respect to the perpendicular line between the metal source and the planar substrate holder. The depositions were carried out at a base pressure of $\sim 2 \times 10^{-5}$ mbar inside the e-beam evaporator chamber. A deposition rate of $1.2 \AA / \mathrm{s}$ was kept constant. The Ag NPs patterned was checked by FEG: SEM measurement.

\section{b) Thermal Evaporator:}

GLAD technique has been carried out to synthesize the pure Ag (MTI, USA) NPs on n-type $\mathrm{Si}<100>$ substrate. The substrate was azimuthally rotated with constant speed of $460 \mathrm{rpm}$ at an orientation of $85^{\circ}$ with respect to the perpendicular line between the metal source and the planar substrate holder. The depositions were carried out at a base pressure of $\sim 2$ $\times 10^{-5}$ mbar inside the thermal evaporator chamber. The dimmestar voltage was $25 \mathrm{mV}$ and time was 3 minutes to deposit the particles over the substrate.

\section{c) Methodology:}

Here we have proposed for the first time the structural Nanoparticle Detection using image processing:

1) Binarize the image using a threshold value calculated using Otsu's method. [8]

2) Use morphological erosion operation on the binarised image.

3) Use connected component analysis to remove the small detected segments.

4) Label every selected nanoparticle. [9]

5) Calculate their boundaries and area. [10]

6) Calculate the irregularity of nanoparticles. [11]

7) Calculate the length of the detected nanoparticle

\section{Flowchart:}

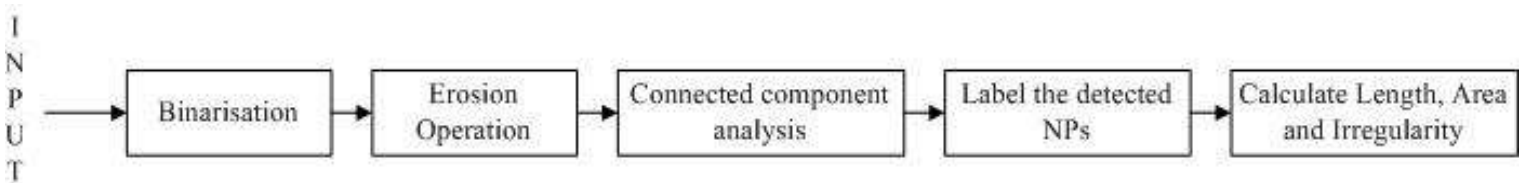

\section{Feature Calculated:}

1) Length of the nano particles: Nanoparticles length was measured by calculating the distance between two farthest point in the nanoparticle boundary.

2) Irregularity in a shape: Irregularity in the shape of each nanoparticles derived by calculating the interior angles of the vertices of the detected nanoparticles boundary.
3) Area of the nano particles: The number of pixels inside a nanoparticle is giving the area of the nano particles. The area was converted in $\mathrm{nm}$ unit after multiplying with scaling factor.

\section{RESULTS AND DISCUSSION}

Nanoparticles generated from Thermal and E-beam method are compared based on their length, area and irregularity in shape. Average size is smaller for thermally generated nanoparticles than nanoparticles generated using thermal (figure 1 and 
Proceedings of the 2nd International Conference on Inventive Computation Technologies ( ICICT 2017) IEEE Xplore Compliant - Part Number:CFP17K52-ART, ISBN:978-1-5090-6697-1

2) and E-beam method (figure 3 and 4). Irregularity is almost same for all of them. Low standard deviation for length and area of nanoparticles generated from E-beam and thermal process proves the uniformity of nanoparticles. E-beam generated particles are more prominent.

TABLE 1. Mean and standard deviation of paricle sizes

\begin{tabular}{|c|c|c|c|c|c|c|}
\hline Nanopar & \multicolumn{2}{|c|}{ Length(nm) } & \multicolumn{2}{c|}{ Area $\left(\mathbf{n m}^{\mathbf{2}}\right)$} & \multicolumn{2}{c|}{ Irregularity $\left.\mathbf{(}^{\mathbf{9}}\right)$} \\
\cline { 2 - 7 } $\begin{array}{c}\text { ticle } \\
\text { Generati } \\
\text { on }\end{array}$ & $\begin{array}{c}\text { Mea } \\
\text { method }\end{array}$ & $\begin{array}{c}\text { Stand } \\
\text { ard } \\
\text { Deviat }\end{array}$ & $\begin{array}{c}\text { Mea } \\
\text { ion }\end{array}$ & $\begin{array}{c}\text { Stand } \\
\text { ard } \\
\text { Deviat } \\
\text { ion }\end{array}$ & $\begin{array}{c}\text { Mea } \\
n\end{array}$ & $\begin{array}{c}\text { Stand } \\
\text { ard } \\
\text { Deviat } \\
\text { ion }\end{array}$ \\
\hline Thermal & 5.13 & 1.3571 & 9.25 & 2.819 & 206. & 10.74 \\
& & & 9 & 8 & 352 & 3 \\
\hline E-beam & 10.6 & 1.575 & 21.1 & 4.284 & 202. & 10.75 \\
& 09 & 0 & 17 & & 216 & 3 \\
\hline
\end{tabular}

Comparison of the largest NPs generated using different methods concludes that ebeam generated

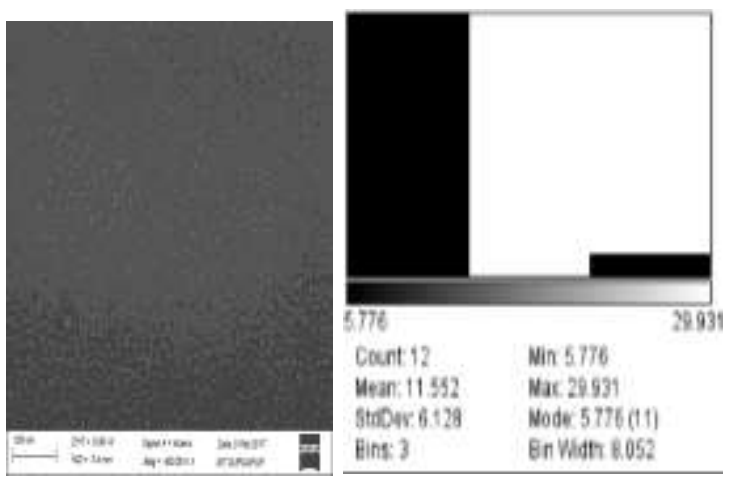

Fig. 1. FEGSEM image of Ag NPs prepared by thermal evaporator system and its particle histogram
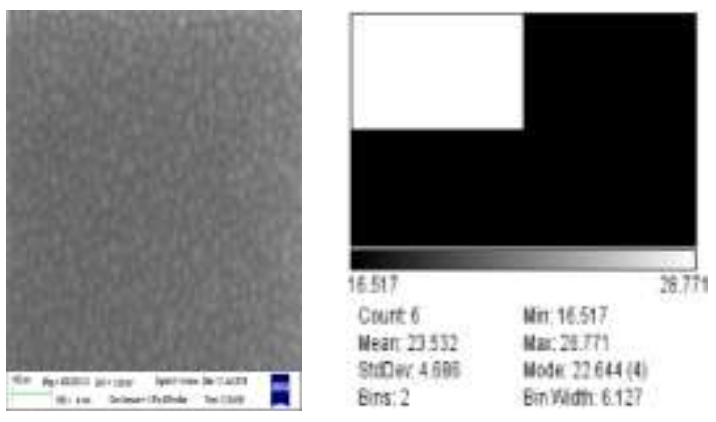

Fig.3. FEGSEM image of Ag NPs prepared by E-beam evaporator system and its particle histogram nanoparticles are bigger and prominent compared to thermal process.

TABLE 2. Size of particles in terms of length and area occupied

\begin{tabular}{|c|c|c|}
\hline $\begin{array}{c}\text { Nanoparticle } \\
\text { Generation method }\end{array}$ & Length(nm) & Area(nm $\left.{ }^{2}\right)$ \\
\hline Thermal & 16.8280 & 35.609 \\
\hline E-beam & 35.98 & 77.81 \\
\hline
\end{tabular}

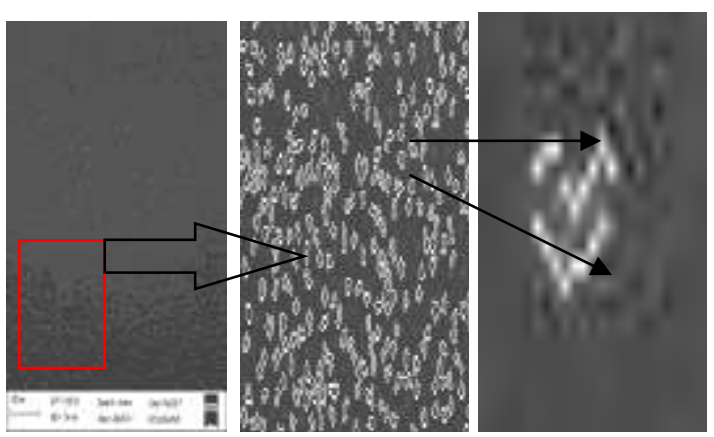

Fig. 2 (a) Original Image (b) Detection NPs from the marked area of original Image (c) The largest NPs in the sample.

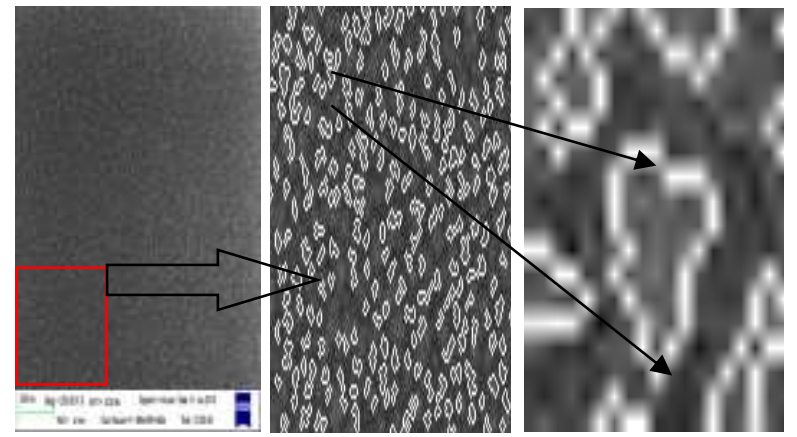

Fig.4. (a) Original Image (b) Detected NPs from the marked area of original Image (c) The largest NPs in the sample 
Proceedings of the 2nd International Conference on Inventive Computation Technologies ( ICICT 2017) IEEE Xplore Compliant - Part Number:CFP17K52-ART, ISBN:978-1-5090-6697-1

\section{CONCLUSION}

In conclusion we have done the comparative morphological study of Ag nanoparticles fabricated by E-beam evaporation method and thermal evaporation method by Image processing technique. The results project that the particles grown by E-beam evaporator is most prominent than Thermal evaporation system.

\section{ACKNOWLEDGEMENT}

Authors are thankful to the Department of Physics, National Institute of Technology, Durgapur and Electronics and Communication Engineering, National Institute of technology, Agartala for using the laboratory facility and Aurora Engineering college and Jadavpur University for financial support.

\section{REFERENCES}

[1]. A. Vilchis-Nestor, V. Sánchez-Mendieta, M. Camacho-López, R. Gómez-Espinosa, M. Camacho-López, J. Arenas-Alatorre, Solventless synthesis and optical properties of $\mathrm{Au}$ and $\mathrm{Ag}$ nanoparticles using Camellia sinensis extractMater. Lett., 62 (2008), p. 3103

[2]. Wan, Y., et al.: Quasi-spherical silver nanoparticles: Aqueous synthesis and size control by the seed-mediated Lee-Meisel method. J. Colloid Interface Sci. 394, 263-268 (2013).

[3]. P. Asanithi, S. Chaiyakun and P. Limsuwan, Growth of Silver Nanoparticles by DC Magnetron Sputtering, Hindawi Publishing Corporation Journal of Nanomaterials Volume 2012, Article ID 963609, 8 pages, 2012.

[4]. A. Gurav, T. Kodas, L. Wang, E. Kauppinen J. Joutsensaari Chem.
Generation of nanometer-size fullerene particles via vapor condensation, Phys. Lett., 218 (1994), p. 304

[5]. F. Kruis, H. Fissan, B. Rellinghaus, Sintering and evaporation characteristics of gas-phase synthesis of size-selected PbS nanoparticle , Mater. Sci. Eng. B, 69 (2000), p. 329

[6]. Messier, R. Gehrke, T. Frankel, C. Venugopal, V. C. Otaño, W.and Lakhtakia, A. (1997), Journal of Vacuum Science Technology. A, v.15, pp. 21482152.

[7]. S. Chakrabartty, A. Mondal, M. B. Sarkar, B. Choudhuri, A. K. Saha, and A. Bhattacharyya, "TiO2 Nanoparticles Arrays Ultraviolet-A Detector with $\mathrm{Au}$ Schottky Contact" IEEE Photonics Technology Letters, Vol. 26, No. 11, 2014.

[8]. N. Otsu, "A Threshold Selection Method from Gray-Level Histograms," IEEE Transactions on Systems, Man, and Cybernetics, Vol. 9, No. 1, pp. 62-66, 1979.

[9]. L. Di Stefano, A. Bulgarelli, A simple and efficient connected components labeling algorithm, International Conference on Image Analysis and Processing, pp. 322-327, 1999.

[10]. Salembier, P., Oliveras, A. and Garrido, L., 1998. Antiextensive connected operators for image and sequence processing. IEEE Transactions on Image Processing, 7(4), pp.555-570.

[11]. Araki, T., Ikeda, N., Molinari, F., Dey, N., Acharjee, S.M., Saba, L., Nicolaides, A. and Suri, J.S., 2014. Effect of geometric-based coronary calcium volume as a feature along 
Proceedings of the 2nd International Conference on Inventive Computation Technologies ( ICICT 2017) IEEE Xplore Compliant - Part Number:CFP17K52-ART, ISBN:978-1-5090-6697-1

with its shape-based attributes for cardiological risk prediction from low contrast intravascular ultrasound. Journal of Medical Imaging and Health Informatics, 4(2), pp.255-261. 